\title{
Cardiac effects of growth hormone in short normal children: results after four years of
} treatment

\author{
P E F Daubeney, E S McCaughey, C Chase, J M Walker, Z Slavik, P R Betts,
} S A Webber

\begin{abstract}
Growth hormone excess is known to have adverse effects on the heart. The long term cardiac effects of growth hormone given to short normal children as part of a prospective randomised controlled trial of growth hormone treatment (Genotropin $30 \mathrm{IU} / \mathrm{m}^{2} /$ week $v$ no treatment) were therefore investigated. Echocardiographic findings are presented for 28 children who have been followed up for a minimum of four years.
\end{abstract}

At the outset, the treated $(n=15)$ and untreated groups $(n=13)$ did not differ for any anthropometric or echocardiographic parameter. Their mean (SD) age at onset was $7.8(0.5)$ years. After four years of treatment mean height SD score increased from -2.4 to -1.2 compared with no change $(-2 \cdot 5)$ in the untreated group. Left ventricular posterior wall and septal thickness and left ventricular shortening fraction did not differ between the groups, but a tendency towards increased left ventricular mass was seen in the treatment group (93 $v 73 \mathrm{~g})$. No such differential was observed after indexing left ventricular mass for body surface area $\left(79 v 71 \mathrm{~g} / \mathrm{m}^{2}\right)$ or lean body mass $(3.15 v 3.05 \mathrm{~g} / \mathrm{kg})$.

It is concluded that prolonged growth hormone treatment does not cause important changes to the heart. A tendency towards increased left ventricular mass simply reflects the increase in lean body mass during treatment.

(Arch Dis Child 1995; 72: 337-339)

Keywords: growth hormone, short stature, cardiac function.

Southampton

University Hospitals

Trust, Wessex

Cardiothoracic Centre

P E F Daubeney

C Chase

Z Slavik

S A Webber

Department of Child

Health

E S McCaughey

J M Walker

P R Betts

Correspondence to: Dr S A Webber, Wessex Cardiothoracic Centre, Southampton General Hospital, Tremona Road Southampton SO16 6YD.

Accepted 3 January 1995

No reprints available

introduction in 1985 , there has br marked increase in the use of synthetic growth hormone for the treatment of a number of conditions associated with short stature. Its use in the treatment of idiopathic short stature is also increasing but remains controversial. ${ }^{1}$ It has recently been estimated that one in 10 of all children receiving growth hormone in the UK have idiopathic short stature. ${ }^{2}$ Owing to the paucity of randomised long term trials of growth hormone treatment, potential adverse effects are not well established. Of particular concern is the possibility of adverse cardiovascular effects of long term growth hormone treatment. ${ }^{3}$ We have therefore studied the car- term in an ongoing randomised controlled study of growth hormone in short normal children. ${ }^{4}$

\section{Patients and methods}

STUDY DESIGN

Full details of this prospective randomised study have been given previously. ${ }^{45}$ In brief, 41 short normal children, whose heights were more than 2 SDs below the mean, were enrolled into the study and randomly allocated to either the treated $(n=21)$ or untreated groups $(n=20)$. The treated group received 30 $\mathrm{IU} / \mathrm{m}^{2} /$ week recombinant growth hormone (Genotropin: KabiPharmacia) as daily subcutaneous injections. Fifteen of the 21 children receiving growth hormone treatment have completed four years of treatment. Six children on treatment withdrew from the study, but none due to cardiovascular side effects. Of the untreated children, 13 continue to be followed up. This study, therefore, analyses the cardiovascular findings in the 28 children who have been followed up for at least four years.

\section{PATIENT CHARACTERISTICS}

Mean (SD) age at onset of the trial was $7 \cdot 8$ $(0 \cdot 5)$ years. There was a similar sex distribution in the two groups with seven boys and eight girls in the treated group and seven boys and six girls in the untreated group. As previously described, there were no differences between the groups at the onset of the study for age, sex, height, parental height, birth weight, bone age, or socioeconomic status. ${ }^{5}$ All children were white. All were initially prepubertal. By year 4 none of the boys in the untreated group had reached puberty. Three of the boys in the treated group were Tanner stage 2 . In both groups all girls were in stage 2 or 3 except for one girl in each group who had reached stage 4 . diac effects of giving growth hormone long
ANTHROPOMETRIC DATA

Height, weight, and skinfold thickness (from biceps, triceps, subscapular, and suprailiac sites) were measured every six months as previously described. ${ }^{5}$ Body fat was calculated using the method of Brook and Siri ${ }^{6}$ and hence lean body mass derived (total weight-weight of body fat). Body surface area (BSA) was calculated from the following formula: $\mathrm{BSA}=$ weight ${ }^{0.425} \times$ height $^{0.007184} .^{8}$ Blood pressure was measured at the year 3 examination. 
Table 1 Comparison of treated and untreated groups at year 0 (that is, before start of growth hormone treatment). Data expressed as mean (SD) for treated and untreated groups; difference between means shown with $S E ; p$ value shown for unpaired two tailed t test between groups

\begin{tabular}{|c|c|c|c|c|}
\hline & Treated & Untreated & $\begin{array}{l}\text { Difference } \\
\text { between means }\end{array}$ & $\stackrel{p}{\text { Value }}$ \\
\hline $\begin{array}{l}\text { Anthropometric data } \\
\text { Height (cm) } \\
\text { Height SD score } \\
\text { Weight }(\mathrm{kg}) \\
\text { BSA (m²) } \\
\text { LBM }(\mathrm{kg})\end{array}$ & $\begin{array}{l}111(3) \\
-2 \cdot 4(0 \cdot 3) \\
18 \cdot 6(2 \cdot 2) \\
0 \cdot 75(0 \cdot 05) \\
16 \cdot 2(1 \cdot 6)\end{array}$ & $\begin{array}{l}110(3) \\
-2 \cdot 5(0 \cdot 4) \\
18 \cdot 7(1 \cdot 8) \\
0 \cdot 75(0 \cdot 04) \\
16 \cdot 3(1 \cdot 3)\end{array}$ & $\begin{array}{r}1 \cdot 0(0 \cdot 9) \\
0 \cdot 1(0 \cdot 1) \\
-0 \cdot 1(0 \cdot 8) \\
0 \cdot 0(0 \cdot 0) \\
-0 \cdot 1(0 \cdot 6)\end{array}$ & $\begin{array}{l}\text { NS } \\
\text { NS } \\
\text { NS } \\
\text { NS } \\
\text { NS }\end{array}$ \\
\hline $\begin{array}{l}\text { Echocardiographic measurements } \\
\text { Posterior wall (mm) } \\
\text { Septum (mm) } \\
\text { LVIDs (mm) } \\
\text { LVIDd (mm) }\end{array}$ & $\begin{array}{r}6 \cdot 1(1 \cdot 8) \\
5 \cdot 9(1 \cdot 3) \\
22 \cdot 7(3 \cdot 2) \\
35 \cdot 8(4 \cdot 0)\end{array}$ & $\begin{array}{r}5 \cdot 8(1 \cdot 2) \\
6 \cdot 2(1 \cdot 3) \\
21 \cdot 2(5 \cdot 3) \\
33 \cdot 9(5 \cdot 1)\end{array}$ & $\begin{array}{r}0.3(0.6) \\
-0.3(0.5) \\
1.5(1.7) \\
1.9(1.9)\end{array}$ & $\begin{array}{l}\text { NS } \\
\text { NS } \\
\text { NS } \\
\text { NS }\end{array}$ \\
\hline $\begin{array}{l}\text { Echocardiographic derivations } \\
\text { Fractional shortening }(\%) \\
\text { LVM }(\mathrm{g}) \\
\text { LVM index }\left(\mathrm{g} / \mathrm{m}^{2}\right) \\
\text { LVM/LBM }(\mathrm{g} / \mathrm{kg})\end{array}$ & $\begin{array}{l}37 \cdot 0(4 \cdot 2) \\
52 \cdot 8(17 \cdot 1) \\
69 \cdot 9(22 \cdot 2) \\
3 \cdot 25(1 \cdot 0)\end{array}$ & $\begin{array}{l}38 \cdot 1(8 \cdot 7) \\
49 \cdot 1(12 \cdot 7) \\
66 \cdot 7(18 \cdot 8) \\
3 \cdot 08(0 \cdot 86)\end{array}$ & $\begin{array}{l}-1 \cdot 1(2 \cdot 6) \\
3 \cdot 7(6 \cdot 6) \\
3 \cdot 2(8 \cdot 9) \\
0 \cdot 17(0 \cdot 40)\end{array}$ & $\begin{array}{l}\text { NS } \\
\text { NS } \\
\text { NS } \\
\text { NS }\end{array}$ \\
\hline
\end{tabular}

For abbreviations see text.

\section{ECHOCARDIOGRAPHY}

Echocardiograms were performed annually from year 0 to 4 using an HP Sonos 1000 or 1500 ultrasound machine (Hewlett Packard). All studies were performed by an experienced echocardiography technician; 3.5 or $5 \mathrm{MHz}$ transducers were used as appropriate. $M$ mode echocardiograms were performed using cross sectional image guidance. All $M$ mode studies were performed using the standard techniques as described by the American Society of Echocardiography. ${ }^{9}$ The following measurements were obtained: thickness of the interventricular septum (IVST) and posterior wall (PWT), both at end diastole, left ventricular end diastolic internal diameter (LVIDd) and left ventricular end systolic diameter (LVIDs). From these parameters the following were derived:

$$
\begin{gathered}
\text { FS of left ventricle }(\%)=100(\mathrm{LVIDd}-\mathrm{LVIDs}) / \mathrm{LVIDd} \\
\mathrm{LVM}(\mathrm{g})= \\
1.04\left([\mathrm{LVIDd}+\mathrm{PWT}+\mathrm{IVST}]^{3}-\mathrm{LVIDd}^{3}\right)-13.6 \\
\mathrm{LVM} \text { indexed for BSA }\left(\mathrm{g} / \mathrm{m}^{2}\right)=\mathrm{LVM} / \mathrm{BSA} \\
\mathrm{LVM} \text { indexed for LBM }(\mathrm{g} / \mathrm{kg})=\mathrm{LVM} / \mathrm{LBM}
\end{gathered}
$$

$\mathrm{FS}=$ fractional shortening, $\mathrm{LVM}=$ left ventricular mass, ${ }^{10} \mathrm{LBM}=$ lean body mass.

STATISTICAL ANALYSIS

\begin{tabular}{|c|c|c|c|c|}
\hline & Treated & Untreated & $\begin{array}{l}\text { Difference } \\
\text { between means }\end{array}$ & $\stackrel{p}{\text { Value }}$ \\
\hline $\begin{array}{l}\text { Anthropometric data } \\
\text { Height }(\mathrm{cm}) \\
\text { Height SD score } \\
\text { Weight }(\mathrm{kg}) \\
\text { BSA }\left(\mathrm{m}^{2}\right) \\
\text { LBM }(\mathrm{kg})\end{array}$ & $\begin{array}{l}141(5) \\
-1 \cdot 2(0 \cdot 5) \\
34 \cdot 3(4 \cdot 7) \\
1 \cdot 16(0 \cdot 10) \\
29 \cdot 0(3 \cdot 8)\end{array}$ & $\begin{array}{l}131(5) \\
-2 \cdot 5(0 \cdot 7) \\
29 \cdot 0(5 \cdot 4) \\
1 \cdot 03(0 \cdot 10) \\
23 \cdot 8(3 \cdot 0)\end{array}$ & $\begin{array}{l}10(1 \cdot 9) \\
1 \cdot 3(0 \cdot 2) \\
5 \cdot 3(1 \cdot 9) \\
0 \cdot 13(0 \cdot 04) \\
5 \cdot 2(1 \cdot 3)\end{array}$ & $\begin{array}{c}<0.0005 \\
<0.0005 \\
0.01 \\
0.001 \\
<0.0005\end{array}$ \\
\hline $\begin{array}{l}\text { Echocardiographic measurements } \\
\text { Posterior wall (mm) } \\
\text { Septum (mm) } \\
\text { LVIDs (mm) } \\
\text { LVIDd (mm) }\end{array}$ & $\begin{array}{r}7 \cdot 2(1 \cdot 6) \\
7 \cdot 3(1 \cdot 4) \\
27 \cdot 5(3 \cdot 0) \\
40 \cdot 6(4 \cdot 5)\end{array}$ & $\begin{array}{r}7 \cdot 6(1 \cdot 9) \\
7 \cdot 2(2 \cdot 2) \\
22 \cdot 9(4 \cdot 6) \\
35 \cdot 7(4 \cdot 9)\end{array}$ & $\begin{aligned}-0.4(0 \cdot 7) \\
0 \cdot 1(0 \cdot 7) \\
4 \cdot 6(1 \cdot 4) \\
4 \cdot 9(1 \cdot 8)\end{aligned}$ & $\begin{array}{l}\text { NS } \\
\text { NS } \\
0.006 \\
0.012\end{array}$ \\
\hline $\begin{array}{l}\text { Echocardiographic derivations } \\
\text { Fractional shortening }(\%) \\
\text { LVM }(\mathrm{g}) \\
\text { LVM index }\left(\mathrm{g} / \mathrm{m}^{2}\right) \\
\text { LVM/LBM }(\mathrm{g} / \mathrm{kg})\end{array}$ & $\begin{array}{l}32 \cdot 0(4 \cdot 7) \\
92 \cdot 9(33 \cdot 0) \\
78 \cdot 9(25 \cdot 0) \\
3 \cdot 15(0 \cdot 89)\end{array}$ & $\begin{array}{l}36 \cdot 1(7 \cdot 3) \\
73 \cdot 2(25 \cdot 7) \\
70 \cdot 7(21 \cdot 1) \\
3 \cdot 05(0 \cdot 87)\end{array}$ & $\begin{array}{c}-4 \cdot 1(2 \cdot 3) \\
19 \cdot 7(11 \cdot 3) \\
8 \cdot 2(8 \cdot 8) \\
0 \cdot 1(0 \cdot 3)\end{array}$ & $\begin{array}{l}\text { NS } \\
0 \cdot 09 \\
0 \cdot 36 \\
0.75\end{array}$ \\
\hline
\end{tabular}

Data are expressed as mean (SD). Height data

Table 2 Comparison of treated and untreated groups at year 4. Data expressed as mean (SD) for treated and untreated groups; difference between means shown with SE; $p$ value shown for unpaired two tailed $\mathrm{t}$ test between groups

For abbreviations see text. are also expressed as SD scores. Treated and untreated groups were compared (at years 0 and 4) using the two tailed, two sample $t$ test; $p$ values $<0.05$ were considered significant.

\section{Results}

At the beginning of the study there were no significant differences between the two groups for any demographic, anthropometric, or echocardiographic variable or derivative (table 1).

ANTHROPOMETRIC DATA (TABLE 2)

There was an excellent response to growth hormone with the treated group consistently taller than the untreated group at each year of the study. The difference at year 4 being 141 (5) $v 131(5) \mathrm{cm}(\mathrm{p}<0.0005)$. Height SD score increased from $-2.4(0.3)$ to $-1.2(0.5)$ in the treated group, compared with no change in the untreated group (-2.5 (0.4) at 0 and 4 years). Weight, body surface area, and lean body mass were also greater in the treated group at year 4 $(p=0.01,0.001$, and 0.0004 respectively).

\section{BLOOD PRESSURE}

There was no difference between the systolic blood pressures of the treated and untreated groups at year $3(97(8) v 92(8) \mathrm{mm} \mathrm{Hg}$ ). The diastolic pressure, however, was slightly increased (64 (7) $v 57$ (6) $\mathrm{mm} \mathrm{Hg}$; $=0.016$ ).

ECHOCARDIOGRAPHY: DIMENSIONS (TABLE 2) There was no significant difference in the thickness of the posterior wall and septum at year 4 between treated and untreated groups. Left ventricular internal dimensions were significantly larger in the treated group both in systole $(27.5(3.0)$ v $22.9(4.6) \mathrm{mm} ; \mathrm{p}=0.006)$ and diastole $(40.6(4.5)$ v $35.7(4.9) \mathrm{mm}$; $\mathrm{p}=0.012$ ).

ECHOCARDIOGRAPHY: DERIVATIONS (TABLE 2) There was no statistically significant difference in the left ventricular shortening fraction between the groups. Left ventricular mass was larger in the treatment group during each year of the study. By year 4 the difference was $20 \mathrm{~g}$, though this did not reach statistical significance (93 (33) $v 73$ (26) $\mathrm{g} ; \mathrm{p}=0.09$ ). When left ventricular mass was indexed for body surface area and lean body mass, this differential was reduced $\left(79\right.$ (25) $v 71$ (21) $\mathrm{g} / \mathrm{m}^{2} ; \mathrm{p}=0.36$ and $3.15(0.89) v 3.05(0.87) \mathrm{g} / \mathrm{kg} ; \mathrm{p}=0.75$ respectively).

\section{Discussion}

Synthetic growth hormone treatment is an accepted form of treatment for growth hormone deficiency. In recent years increasing numbers of short normal children have been started on long term courses of growth hormone, even though the efficacy and adverse effects of this treatment are not fully 
established. ${ }^{145}$ Of particular concern is the possibility of adverse cardiovascular effects when growth hormone is given over a prolonged period. Conditions with excessive growth hormone secretion are known to be associated with an increase in cardiovascular morbidity and mortality. ${ }^{11}$ Acromegalic patients frequently have increased left ventricular mass, which may occur independently of systemic hypertension. ${ }^{12-14}$ These observations suggest that growth hormone has a direct anabolic effect on the heart and some authors have referred to a 'specific acromegalic cardiomyopathy'. ${ }^{15}$

It remains to be determined whether growth hormone given as replacement treatment or as treatment to short normal children has adverse cardiovascular effects. Growth hormone given as replacement treatment to growth hormone deficient adults has produced conflicting results. Cuneo and colleagues reported an increase in left ventricular mass during replacement treatment without a change in mean arterial pressure. ${ }^{3}$ By contrast, Jorgensen and colleagues noted no difference in left ventricular mass in growth hormone deficient adults randomised to growth hormone replacement or placebo. ${ }^{16}$ Both these studies involved treatment for six months or less. Short normal children are frequently given growth hormone in a dosage approximately twice that for replacement treatment (for example $30 v 15$ $\mathrm{IU} / \mathrm{m}^{2} /$ week), often for several years. ${ }^{4}$ It is clearly imperative to establish that there are no long term cardiovascular (or other) adverse effects of this controversial treatment. Only one prior study has addressed this issue. Barton and colleagues measured left ventricular dimensions and wall thickness in a group of short normal children receiving two different doses of growth hormone $(20$ or 40 $\mathrm{IU} / \mathrm{m}^{2} /$ week) or no treatment. ${ }^{17}$ After one year the control patients were randomised to one of the treatment groups. Echocardiographic findings were reported after one year of treatment. Increment in left ventricular mass was greater in the high dose treatment group, but was considered to be fully explained by the greater increase in body size (though the method of indexing for change in body size was not stated). It was concluded that no adverse effects on the heart are present after one year of growth hormone treatment, but 'whilst these preliminary results are reassuring, much longer follow up studies of these patients are required....'

We have performed a unique, long term randomised study of growth hormone treatment in short normal children. ${ }^{4}$ The children have now completed four years of follow up and the study is ongoing. A particular strength of this study has been the maintained follow up of the control subjects. We have therefore had the opportunity to study the cardiovascular effects of long term growth hormone and contrast these to a well matched control group. At the onset of the study echocardiographic findings were almost identical between the two groups. After four years of treatment a trend towards increased left ventricular mass was present in the treated group. However, growth in this group was also clearly superior. After indexing for body surface area, these differences diminish. We previously noted a marked lipolytic effect of growth hormone treatment. ${ }^{4}$ Indexing left ventricular mass for lean body mass, to control for variations in total body fat, abolished any difference in left ventricular mass between the two groups.

These findings strongly suggest that four years of high dose growth hormone treatment does not have adverse effects on left ventricular wall thickness or mass. Systolic function as assessed by left ventricular shortening fraction also remains unaltered. Abnormalities of diastolic function have not been addressed by this study and warrant investigation. Although these results are reassuring, the role of growth hormone in this group of children still remains controversial. ${ }^{15}$

PD is supported by the Wessex Cardiac Trust.

1 Underwood LE, Rieser PA. Is it ethical to treat healthy short children with growth hormone? Acta Paediatr Scand Suppl 1989; 362: 18-23.

2 KIGS UK Collaborative Group. Kabi international growth study - United Kingdom report 1991. Milton Keynes: Kabi International, 1991

3 Cuneo RC, Salomon F, Wilmshurst P, et al. Cardiovascular effects of growth hormone treatment in growth-hormonedeficient adults: stimulation of the renin-aldosterone system. Clin Sci 1991; 81: 587-92.

4 Walker JM, Bond SA, Voss LD, Betts PR, Wootton SA, Jackson AA. Treatment of short normal children with growth hormone - a cautionary tale? Lancet 1990; 336: growth hor $1331-4$.

5 McCaughey ES, Mulligan J, Voss LD, Betts PR. Growth and metabolic consequences of growth hormone treatment in prepubertal short normal children. Arch Dis Child 1994; 71: 201-6.

6 Brook CDG. Determination of body composition of children from skinfold measurements. Arch Dis Child 1971; 46: 182-4

7 Siri WE. The gross composition of the body. Advances in Biological and Medical Physics 4. New York: Academic Press, 1956: 239-80.

8 DuBois D, DuBois EF. Clinical calorimetry: X. A formula to estimate the approximate surface area if height and weight be known. Arch Intern Med 1916; 17: 863-71.

9 Sahn DJ, DeMaria A, Kisslo J, Weyman A. The Committee on M-Mode Standardization of the American Society of Echocardiography. Recommendations regarding quantitation in M-mode echocardiography: results of a survey of echocardiographic measurements. Circulation 1978; 58: 1072-81.

10 Devereux RB, Reichek N. Echocardiographic determination of left ventricular mass in man. Anatomic validation of the method. Circulation 1977; 55: 613-8.

11 Wright AD, Hill DM, Lowy C, Russell Fraser T. Mortality in acromegaly. $Q \mathcal{F} \mathrm{Med} 1970$; 39: 1-16.

12 Martins JB, Kerber RE, Sherman BM, Marcus ML, Ehrhardt JC. Cardiac size and function in acromegaly. Circulation 1977; 56: 863-9.

13 Smallridge RC, Rajfer S, Davia J, Schaaf M. Acromegaly and the heart: an echocardiographic study. $A m \ngtr$ Med 1979; 66: 22-7.

14 Savage DD, Henry WL, Eastman RC, Borer JS, Gorden P. Echocardiographic assessment of cardiac anatomy and function in acromegalic patients. Am F Med 1979; 67: 823-9.

15 Chanson P, Timsit J, Masquet C, et al. Cardiovascular effects of the somatostatin analog octreotide in acromegaly. Ann Intern Med 1990; 113: 921-5.

16 Jorgensen JOL, Pedersen SA, Thuesen L, et al. Beneficial effects of growth hormone treatment in GH-deficient effects of growth hormone trea
adults. Lancet 1989; i: 1221-5.

17 Barton JS, Cullen S, Hindmarsh PC, Brook CGD, Preece MA. Growth hormone treatment in idiopathic short stature: a preliminary analysis of cardiovascular effects. Acta Paediatr Suppl 1992; 383: 35-8. 